\title{
A COMPARISON OF MEDICAL AND SURGICAL TREATMENT OF MITRAL STENOSIS
}

\author{
BY \\ D. McC. BOYLE \\ From the Royal Victoria Hospital, Belfast
}

Received November 25, 1960

The efficacy of mitral valvotomy in the relief of critical mitral stenosis is not in doubt. It has, however, been noted that lesser degrees of mitral stenosis may not prevent survival to an old age. The influence of operation on the overall long-term prognosis of patients with mitral stenosis will be determined only by comparing the prognosis of medically treated patients with that of those subjected to surgery. There has been recent demand for such a comparison (Annotation, Lancet, 1960). A prospective study of this type is very difficult, but it was thought that a retrospective study in which the prognosis in a surgically treated group was compared with the reported prognosis of medically treated groups might be of value. In this paper the prognosis of a group of patients subjected to mitral valvotomy is compared with that of three medically treated groups with mitral stenosis reported by Grant (1933), by Olesen (1955), and by Rowe et al. (1960).

\section{Results in Group Treated Surgically}

Six hundred and twenty-six patients have had mitral valvotomy in this hospital up to May 1959 , but the 28 who were pregnant at the time of operation were excluded from this series. The results of the remaining 598 have been compared with the medically treated series of Grant, of Olesen, and of Rowe et al.

Of the surgically treated series, 77 per cent were women. The average age of the patients was 33.8 years and the ages varied from 15 to 63 years. Atrial fibrillation occurred before operation in 27 per cent of them. Their disability placed 24 per cent of them in Grade IV, 53 per cent in Grade III, and the remaining 23 per cent in Grade II (New York Heart Association Classification 1946).

Clinical signs thought to indicate some degree of associated mitral regurgitation were found in 15 per cent. At operation palpable mitral reflux was felt by the surgeon in 14 per cent. Nine per cent were thought to have the early diastolic murmur of aortic regurgitation, but few of these had peripheral signs of this. Right ventricular hypertrophy (Milnor, 1957) was present in 23 per cent and the Graham Steell murmur of pulmonary regurgitation in 15 per cent. Eight per cent had preoperative embolism-19 per cent of those with atrial fibrillation before operation and 5 per cent of those in sinus rhythm.

The operation performed in the majority of cases $(61 \%)$ was finger fracture of the valve. If this proved unsuccessful the valve commissures were divided with a valvotome $(31 \%)$ or, more recently, with a transventricular dilator (Logan et al., 1959) $(8 \%)$. The later patients have had more effective operation. In the first hundred patients of the series, only six had both commissures divided to the valve ring, and in the last hundred the figure was forty. 13 per cent of patients were thought by the surgeon at the time of operation, or clinically six months after operation, to have had a degree of traumatic mitral regurgitation: in the majority this was slight.

Operative mortality rate was $4 \cdot 2$ per cent. This was highest in a small group of patients in 377 
intractable congestive failure $(17 \%)$. Mortality rate was also high in patients with electrocardiographic evidence of right ventricular hypertrophy $(7.5 \%)$. Operative mortality was nil in patients aged under twenty years and 1.6 per cent in patients with functional disability of Grade II.

Embolic episodes occurred during or immediately after operation in 4 per cent of the patientsmore often $(11 \%)$ in those with atrial fibrillation than in those with sinus rhythm $(2 \%)$. The risk was greatest in patients with a previous history of emboli.

In the series 7 per cent required repeat operation, and four patients have had three operations: 17 per cent of those undergoing a second valvotomy had at the first operation at least one commissure split to the valve ring. The mortality rate of repeat valvotomy was 6 per cent.

The results of operation as assessed at post-operative review are summarized in Fig. 1. This

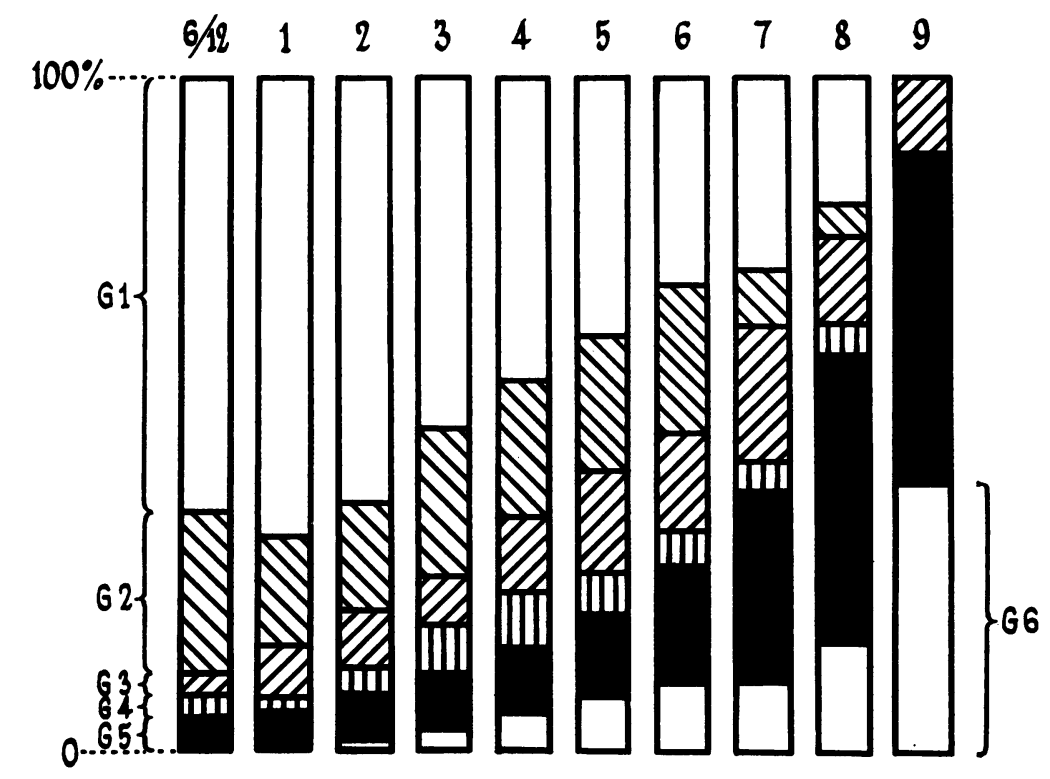

FIG. 1.-Histogram showing the percentage of patients in different clinical groups at the post-operative reviews (six months and then yearly).

$\begin{array}{llll}\text { G1 } & \text { Clinical Grade I } & \text { G4 } & \text { Clinical Grade IV } \\ \text { G2 } & \text { Clinical Grade II } & \text { G5 } & \text { Dead } \\ \text { G3 } & \text { Clinical Grade III } & \text { G6 } & \text { Repeat operation performed. }\end{array}$

shows the percentage of patients in the various grades of functional disability (Grades I-IV, New York Heart Association classification), the percentage who required a repeat operation, and the percentage who died. It is seen that the percentage of patients remaining in Grade I or II functional disability gradually decreased, while the number who have died or have required a repeat operation gradually increased.

It was found, as expected, that younger patients did better than older patients, that those with sinus rhythm did better than those with atrial fibrillation, and that patients with severe preoperative disability did not do as well as those less severely incapacitated. Inadequate splitting of the valve cusps and mitral cusp calcification were also associated with a less good prognosis. It was noted that 62 per cent of the patients with electrocardiographic evidence of right ventricular hypertrophy developed normal cardiograms and 73 per cent of those thought to have pulmonary regurgitation lost the Graham Steell murmur.

\section{Comparison With Medically Treated Series}

Grant (1933) observed the prognosis of 1000 medically treated patients with heart disease over a ten-year period (1920-1930). From this study it is possible to trace the prognosis of 321 patients 
who had mitral stenosis (with or without a minor degree of aortic regurgitation) and at the beginning of the follow-up corresponded approximately to Grades II, III, and IV of the New York Heart Association. Olesen (1955) followed 351 medically treated patients with mitral stenosis for periods of up to twenty years, starting from 1933. More recently, Rowe et al. (1960) have reviewed the prognosis of 250 medically treated patients with mitral stenosis over a period of ten to twenty years, starting from 1925 . In both these series the criteria used in disability grading corresponded approximately to the grading of the New York Heart Association. It is apparent that comparisons of different series are difficult to evaluate because of the difficulty in obtaining exactly comparable groups.

Prior to the introduction of mitral valvotomy the assessment of the degree of mitral regurgitation associated with mitral stenosis was not considered so important. Because of this many patients of the medically treated series of mitral stenosis may have had a significant degree of mitral regurgitation. A source of error in comparing Grant's series with a surgically treated group is that this medically treated series was composed of ex-servicemen who were being assessed for disability pensions. These patients may have exaggerated their symptoms with resultant classification in higher grades of disability. Another factor complicating comparison is the fact that the prognosis of medically treated patients is gradually improving (Hall et al., 1958).

Table I compares the composition of the present series with those of Grant, Olesen, and Rowe

TABLE I

Comparison of Present Series with the Series Treated Medically

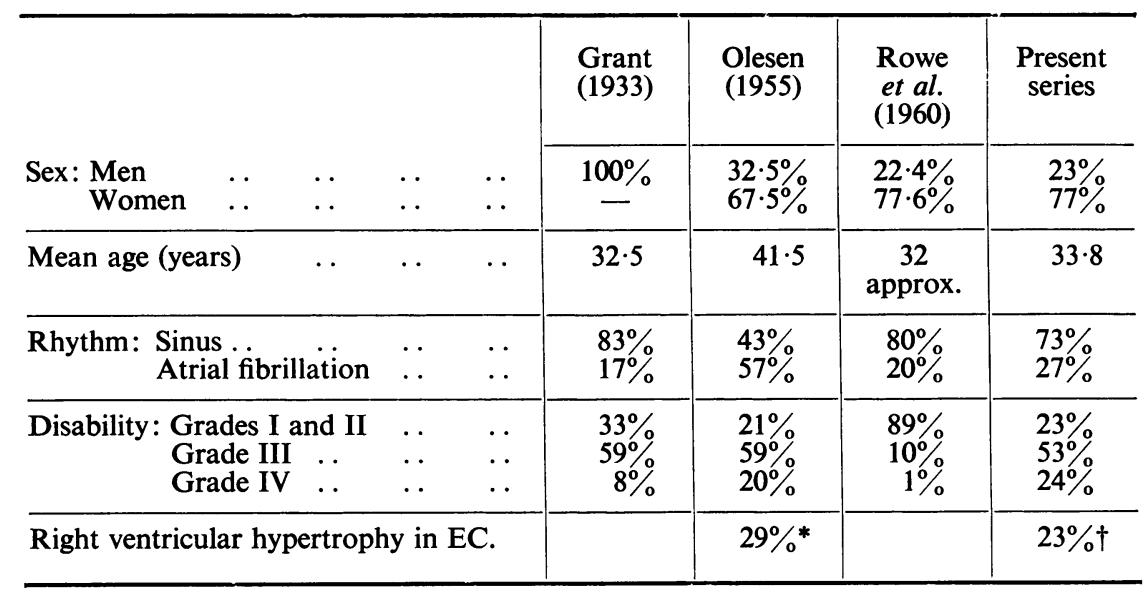

* Right axis deviation.

$\dagger$ Milnor's criteria.

et al. with regard to sex, mean age, rhythm, disability, and electrocardiographic evidence of right ventricular hypertrophy. Grant's series is similar to the present series as regards mean age, but they are all men and the incidence of atrial fibrillation is somewhat lower and the incidence of patients in Grade IV disability much lower. Olesen's series and the present series are similar but in Olesen's series the mean age is higher and the incidence of atrial fibrillation is much higher. The series of Rowe et al. is similar to the present series with regard to sex, age, and rhythm, but the incidence of patients in Grade IV disability is very small.

Fig. 2-7 compare the prognosis of the medically treated series with that of the surgically treated group. In Grades I and II the surgical results were somewhat better than the medical results, (Fig. 2), in Grade III they were better (Fig. 3), and in Grade IV they were very much better (Fig. 4). Fig. 2 shows the percentage survival of surgically treated patients whose functional disability before operation was Grade II in comparison with two of the medically treated series, who at the time their follow-up study was started had a similar degree of disability. It will be seen that after six 
years 92 per cent. of the surgically treated series survived, whereas 83 per cent of Grant's series and 58 per cent of that of Rowe et al. survived.

Fig. 3 shows the percentage survival of surgically treated patients who before operation were in

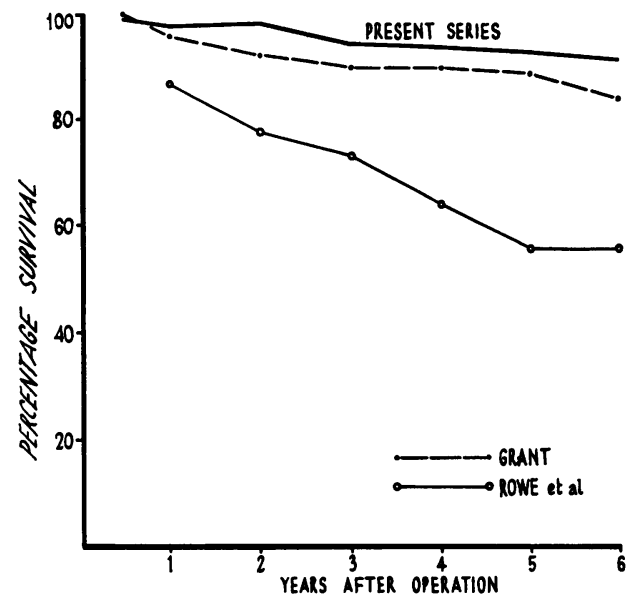

FIG. 2.-Survival rate of patients in Grades I and II initially, in years of follow-up, comparing the present series with the series of Grant and of Rowe et al.

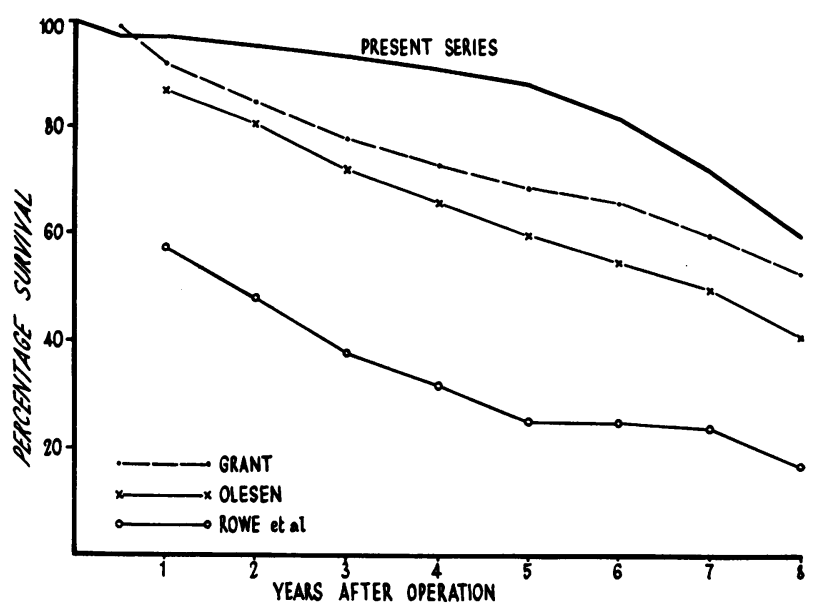

FIG. 3.-Survival rates of patients initially in Grade III, in years of follow-up, comparing the present series with the series of Grant, Olesen, and Rowe et al.

functional disability Grade III in comparison with the medically treated patients who had initially a similar degree of disability. After eight years 61 per cent of the surgically treated series survived, compared with 55 per cent of Grant's series, 42 per cent of Olesen's series, and 20 per cent of the series of Rowe $e t$ al.

Fig. 4 shows the percentage survival of surgically treated patients whose functional disability before operation was Grade IV, in comparison with two of the medically treated series who initially had a similar degree of disability. After seven years 73 per cent of the surgically treated series survived compared with 17 per cent of Grant's series and 7 per cent of Olesen's series.

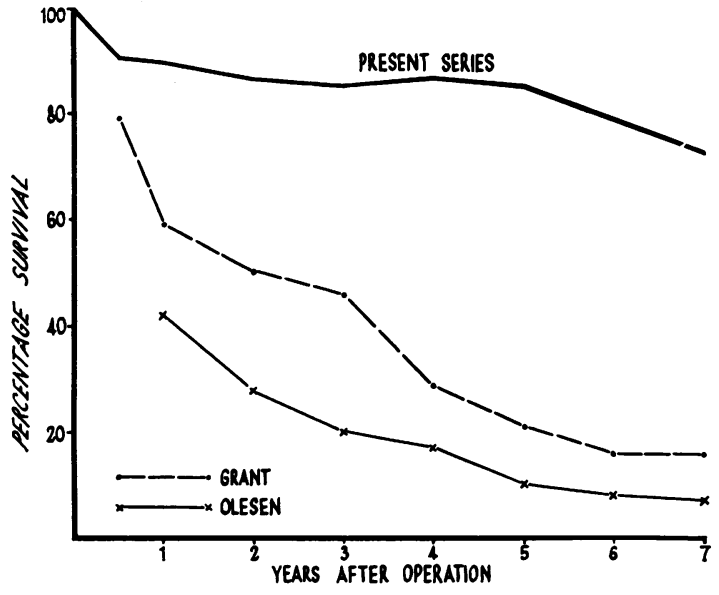

FIG. 4.-Survival rates of patients initially in Grade IV, in years of follow-up, comparing the present series with the series of Grant and Olesen.

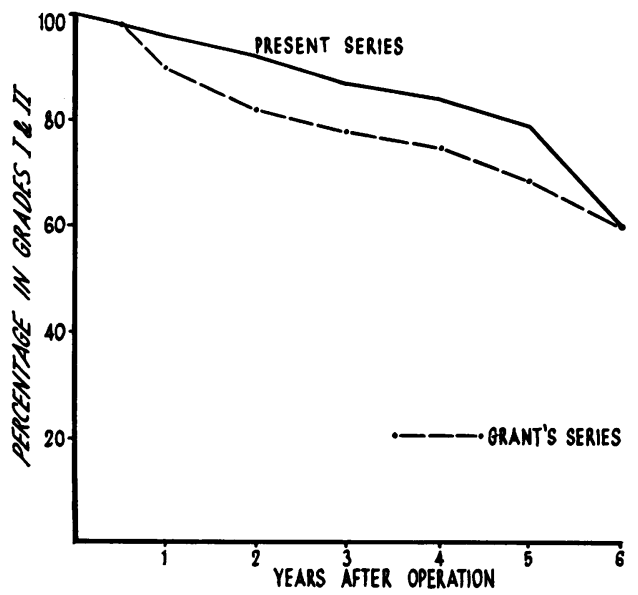

FIG. 5.-Percentage of patients in clinical Grades I and II in the years of follow-up, comparing the present series with Grant's series. Only patients initially in Grades I and II are considered. 
Fig. 5 shows the percentage of patients in functional disability Grade I or II at the review examinations. Patients treated surgically with functional disability Grade II before operation are compared with Grant's medically treated patients who at the start of his follow-up study had a similar degree of disability. The two curves are similar, and after six years 60 per cent of both were in functional disability Grade I or II. The small difference between the two curves may be due to the fact that all patients in functional disability Grade II treated surgically had some additional evidence to suggest high grade mitral stenosis-increased hilar vascularity or electrocardiographic evidence of right ventricular hypertrophy-and so were generally in a more advanced stage of the disease than the patients in Grant's series.

Fig. 6 shows the percentage of surgically treated patients in Grade III before operation whose grading had improved to Grade I or II at the various post-operative reviews. At six months 90 per cent were in Grade I or II but after eight years only 22 per cent. No patient in Grant's series initially Grade III improved in grading during the period of medical follow-up.

Fig. 7 shows similarly the percentage of patients with functional disability Grade I or II at the

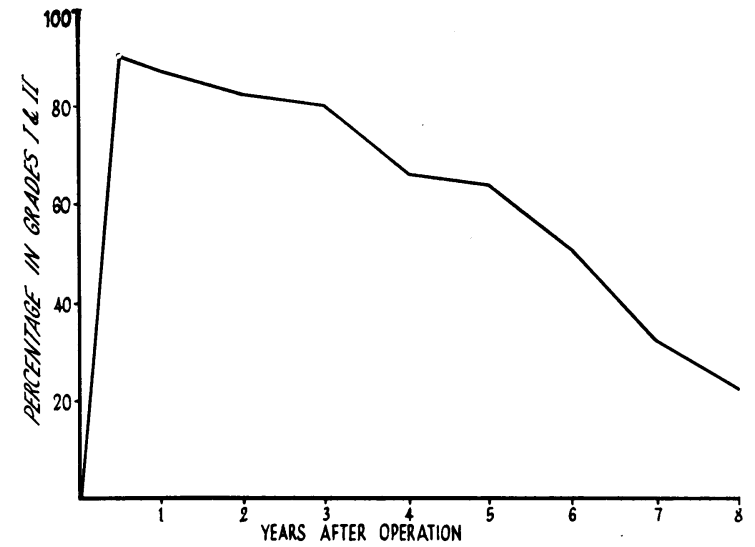

FIG. 6.-Percentage of patients who were initially in clinical Grade III, in Grades I and II in the years of follow-up in the present series. No comparable patients in Grant's series were classified as being in clinical Grades I and II in the follow-up period.

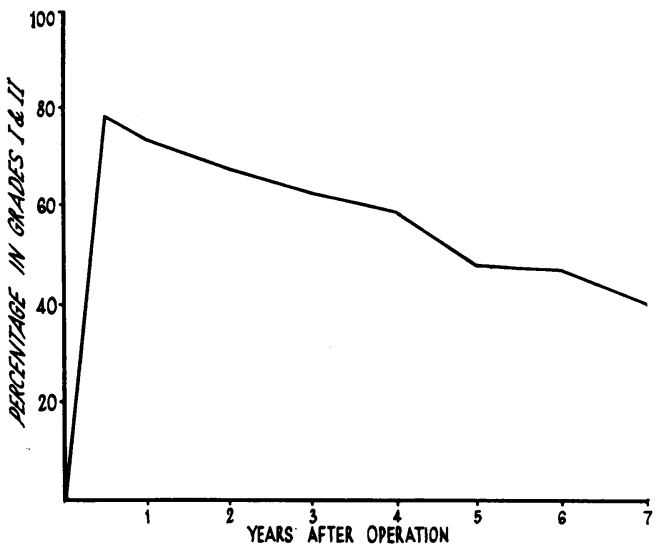

FIG. 7.-Percentage of patients initially in clinical Grade IV, in clinical Grades I and II in the years of follow-up in the present series. No camparable patients in Grant's series were classified as being in clinical Grades I and II in the follow-up period.

review examinations of surgically treated patients who had a functional disability Grade IV before operation. After seven years 45 per cent are in clinical Grade I or II. No patient in Grant's series initially in Grade IV improved sufficiently to be classified as in Grade I or II.

Apart from the prognosis in terms of survival and of functional disability it is of value to compare the incidence of embolism during the follow-up period in the surgically treated patients with that in medically treated patients. In the present series, the incidence of embolism following operation was small, being 1.8 per cent of 1681 patient years. In Bannister's (1960) study of patients in whom valvotomy was deferred the incidence was 4.9 per cent in 472 patient years. Atrial fibrillation was present with equal frequency in both groups $(28 \%$ in Bannister's series; $27 \%$ in the present surgically treated series).

\section{SUMMARY}

The results of mitral valvotomy in a series of 598 patients have been compared with the reported follow-up states of patients with mitral stenosis treated by medical measures. The difficulties of 
such a comparison are noted. The comparison does, however, indicate that patients submitted to surgery have a much better outlook regarding both survival and restoration to reasonably normal health.

The patients in the present series were under the care of Dr. J. F. Pantridge to whom I am indebted for help.

\section{REFERENCES}

Annotation (1960). Lancet, 2, 748.

Bannister, R. G. (1960). Lancet, $2,329$.

Grant, R. T. (1933). Heart, 16, 275.

Hall, P., and Biorck, G. (1958). Acta Rheum. Scand., 4, 70.

Logan, A., and Turner, R. (1959). Lancet, 2, 874.

Milnor, W. R. (1957). Circulation, 16, 348.

New York Heart Association (1946). Nomenclature and Criteria for Diagnosis of Diseases of the Heart, p. 72. P. F. Mallon Inc., New York.

Olesen, K. H. (1955). Mitral Stenosis: a Follow-up of 351 Patients. Copenhagen.

Rowe, J. C., Bland, E. F., Sprague, H. B., and White, P. D. (1960). Ann. intern. Med., 52, 741. 